Sharif University of Technology
Scientia Iranica
SCIENTIA
I RAN I CA

\title{
Stability analysis of arch dam abutments due to seismic loading
}

\author{
H. Mostafaei ${ }^{a}$, M. Sohrabi Gilani ${ }^{b}$ and M. Ghaemian ${ }^{a, *}$ \\ a. Department of Civil Engineering, Sharif University of Technology, Tehran, P.O. Box 11155-9313, Iran. \\ b. Department of Civil Engineering, Faculty of Engineering, University of Guilan, Rasht, Iran. \\ Received 22 February 2015; received in revised form 8 November 2015; accepted 14 May 2016
}

\author{
KEYWORDS \\ Abutment stability \\ analysis; \\ Dynamic analysis; \\ Quasi-static analysis; \\ Safety factor of wedge; \\ Uplift pressure; \\ Londe method.
}

\begin{abstract}
Abutments of concrete arch dams are usually crossed by several joints, which may create some rock wedges. Abutment stability analysis and controlling the probable wedge movements is one of the main concerns in the design procedure of arch dams that should be investigated. For decades, the quasi-static method, due to its simple approach, has been used by most of dam designers. In this study, the dynamic method is presented and the obtained time history of sliding safety factors is compared with the quasi-static results. For this purpose, all three components of Kobe (1979) and Imperial Valley (1940) earthquakes are applied to the wedge, simultaneously, and the magnitude and direction of wedge displacements are calculated based on Newmark method, which is not possible in the quasi-static approach. A 3-D finite element model of Luzzone dam, including damfoundation-reservoir interactions, is used to compute the thrust forces. The obtained results indicate that quasi-static method is more conservative. The importance of uplift pressure effects on the abutment stability is investigated as well. It is shown that the uplift pressure can play a key role in the abutment stability analysis and it is necessary to control the uplift pressure and seepage in arch dam foundations.
\end{abstract}

(C) 2017 Sharif University of Technology. All rights reserved.

\section{Introduction}

The safety of concrete dams is a major challenge for the owners due to their possible failure consequences when subjected to severe earthquake ground motions. One of the most important aspects in the stability of arch dams is the abutment stability. Failure of concrete arch dams showed that the main cause of the destruction of concrete arch dams is the rock abutment instability. The stability analysis of abutment can be performed by using different approaches such as block theory [1], limit equilibrium analysis [2], Distinct-Element Method (DEM), and Finite Element Method (FEM) [3], each with their certain advantages and shortcomings [4]. In

\footnotetext{
*. Corresponding author. Tel.: +982166164242;

Fax: +982166014828

E-mail address: ghaemian@sharif.edu (M. Ghaemian)
}

this regard, it is completely necessary to have proper and thorough analysis in order to evaluate stability of abutments for the purpose of dam safety. Yet, it is not exclusively academic, as amply evidenced by disasters such as the Malapasset Dam abutment failure and the Vajont rock slide [5]. Because of scale effects, stability of abutment varies generally with the wedge size, so the laws governing this variation are not completely known. The rock slopes usually consist of discontinuities such as faults, joints sets, beddings, and layers that must be considered in the abutment analysis.

Stability analysis of arch dam abutments has been the topic of many studies. Headquarters of U.S. Army Corps of Engineering emphasize that the analysis of abutment stability requires very careful application of both engineering geology and rock mechanics and analytical techniques [6]. The sliding Factors of Safety (FS) have been recommended for different loading 
cases [7]. Sohrabi et al. studied the stability of dam abutment including seismic loading. Time histories of safety factors as well as wedge displacement have been presented [8]. Zenz et al. investigated the effect of interaction on abutment stability in concrete arch dams. Accordingly, they found that more sophisticated realistic models showed higher margins to entire system failure and anticipated that the existing model assumptions were conservative, as it was assumed [9].

Peng Lin et al. carried out hazard analysis of reservoir and typical high dams after Wenchuan earthquake [10]. Peng Lin et al. performed 3D geomechanical model tests. The safety factors of dam foundation were computed [11].

In this paper, the stability of the contact wedge of Luzzone arch dam due to static and seismic loadings has been studied based on Londe limit equilibrium method. The quasi-static and dynamic approaches are compared and the effects of different uplift scenarios have been investigated. The modified Newmark method is used to calculate the probable displacements and velocities of the wedge [12].

\section{Stability analysis}

In order to assess the stability of rock wedges, Londe method has been used by many researchers. In this method, the wedges are defined by three probable sliding planes, which have been shown by P1 (O, A, C), P2 (O, B, C), and P3 (O, A, B) in Figure 1. The geometry of each plane is characterized by its area and plane orientation (Dip and Dip direction).

In this method, the wedge is considered rigid and tensile strength of contact surfaces of the wedge is neglected. The cohesion and friction angle of each plane have profound effects on the wedge stability and should be estimated by comprehensive geology and rock mechanics studies. The moments of the reaction

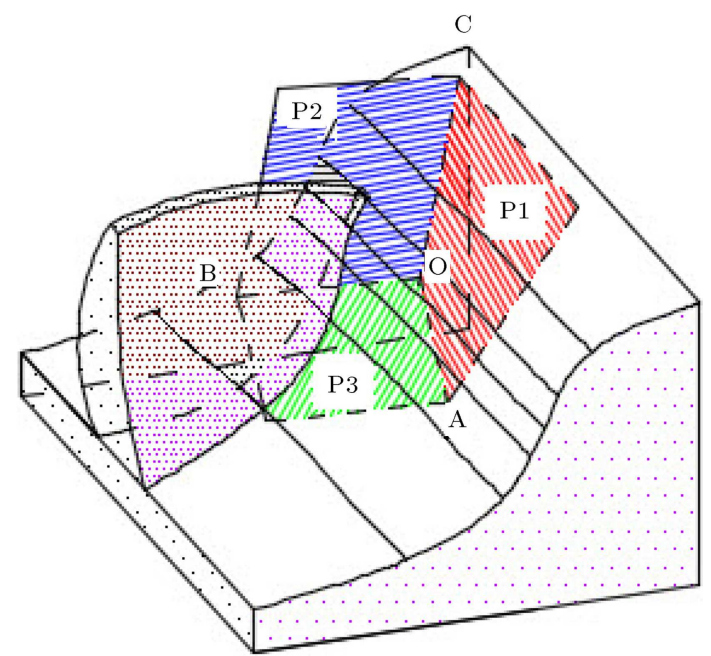

Figure 1. A typical rock wedge and its supporting planes. forces are assumed negligible and their influences on the equilibrium equations are not considered. The wedge failure can only occur in the case of its movement on one or two of its supporting surfaces in the opposite direction of the wedge corner [13].

\subsection{Applied forces}

The applied loads on the wedge can be categorized as static and dynamic (time-dependent) forces. The dead load is encapsulated in the weight of the wedge. The weight of the wedge as a dead load can be calculated by the wedge volume and the specific weight of the rock. The uplift pressure on each plane can be determined due to the water level, geometry and area of the planes, and the performance of the grout curtain. In spite of these two forces, which are constant during the analysis, the inertia and thrust forces are timedependent and their magnitudes and directions will change during seismic loads. It should be mentioned that the thrust forces, which are applied by the dam to the wedge, include the weight of the dam, hydrostatic and hydrodynamic pressures, and seismic loads based on the considered load combinations. The resultant of these applied forces can be calculated as:

$$
F_{r e s}^{W}=F_{w}^{W}+F_{U P}^{W}+F_{E Q}^{W}+F_{T H}^{D}
$$

where $F_{w}^{W}, F_{U P}^{W}, F_{E Q}^{W}$, and $F_{T H}^{D}$ are weight of the wedge, total uplift forces on planes, inertial force of wedge, and the thrust forces of the dam, respectively. Considering the coordinate system that $z$-component corresponds to the vertical direction, the applied forces are represented in a vector notation as follows:

$$
\begin{aligned}
& F_{w}^{W}=\left[\begin{array}{c}
0 \\
0 \\
-m^{W} \times g
\end{array}\right], \\
& F_{U P}^{W}=\left[\begin{array}{c}
U_{X}^{1} \\
U_{Y}^{1} \\
U_{Z}^{1}
\end{array}\right]+\left[\begin{array}{l}
U_{X}^{2} \\
U_{Y}^{2} \\
U_{Z}^{2}
\end{array}\right]+\left[\begin{array}{l}
U_{X}^{3} \\
U_{Y}^{3} \\
U_{Z}^{3}
\end{array}\right], \\
& F_{E Q}^{W}=\left(-m^{W}\right) \times\left[\begin{array}{l}
\ddot{u}_{x}(t) \\
\ddot{u}_{y}(t) \\
\ddot{u}_{z}(t)
\end{array}\right], \\
& F_{E Q}^{W}=\left[\begin{array}{l}
F_{T H-x}^{D}(t) \\
F_{T H-y}^{D}(t) \\
F_{T H-z}^{D}(t)
\end{array}\right],
\end{aligned}
$$

where $m^{W}, U^{1}, U^{2}$, and $U^{3}$ are the mass of the wedge and the uplift forces on planes P1, P2, and P3, respectively. Also $\ddot{u}_{x}(t), \ddot{u}_{y}(t), \ddot{u}_{z}(t)$, and $F_{T H}^{D}(t)$ are three components of ground acceleration time histories and the thrust forces due to the static and seismic 
Table 1. Possible separation or sliding mode.

\begin{tabular}{ccc}
\hline $\begin{array}{c}\text { Separation or } \\
\text { sliding index }\end{array}$ & Definition & Nature of sliding vector \\
\hline $\mathbf{1}$ & All the plane are compressive & Stable \\
$\mathbf{2}$ & $N_{1}$ is compressive & Sliding on plane P1 \\
$\mathbf{3}$ & $N_{2}$ is compressive & Sliding on plane P2 \\
$\mathbf{4}$ & $N_{3}$ is compressive & Sliding on plane P3 \\
$\mathbf{5}$ & $N_{1}$ and $N_{2}$ are compressive & Sliding on intersection P1 and P2 \\
$\mathbf{6}$ & $N_{1}$ and $N_{3}$ are compressive & Sliding on intersection P1 and P3 \\
$\mathbf{7}$ & $N_{2}$ and $N_{3}$ are compressive & Sliding on intersection P2 and P3 \\
$\mathbf{8}$ & All the plane reactions are tensile & Unstable \\
\hline
\end{tabular}

loadings. To calculate the thrust forces, it is needed to develop a three-dimensional finite element model of dam-foundation-reservoir. In the dynamic approach, all three components of earthquake ground motions can be applied to the model simultaneously.

\subsection{Equilibrium equation and sliding modes}

Equilibrium equations can be used to obtain three corresponding reaction forces on the planes $N_{1}, N_{2}$, and $N_{3}$. Due to the fact that the planes are solely compressive, tensile normal forces mean that the planes are opened. When a plane is open, it means that the considered sliding mode is not true and it will lead to the other different sliding modes excluding this plane. Eight possible separation or sliding modes, which are likely to happen, are listed in Table 1. following:

All sliding modes are described briefly in the

- Case 1: The plane normal reaction forces are compressive, which means that all the planes are in contact. Thus, the wedge is perfectly stable;

- Case 2: The normal force on the plane P1 is compressive, but the reactions of planes $\mathrm{P} 2$ and $\mathrm{P} 3$ are in tension. By ignoring the planes P2 and P3 and solving the equilibrium equations, the normal and shear forces on plane P1 are obtained. If the obtained normal force on $\mathrm{P} 1$ is compressive, it means that the assumption is verified and sliding occurs on plane $\mathrm{P} 1$. In this case, the safety factor is obtained as follows:

$$
\mathrm{SF}=\frac{N_{1} \times \tan \left(\varphi_{1}\right)+c_{1} \times A_{1}}{\text { Shear force on plane } \mathrm{P} 1} .
$$

- Case 3: The reaction of plane P2 is compressive and reactions of planes $\mathrm{P} 1$ and $\mathrm{P} 3$ are in tension. This case is similar to Case 2;

- Case 4: The reaction of plane P3 is compressive and reactions of planes $\mathrm{P} 1$ and $\mathrm{P} 2$ are in tension. This case is similar to Case 2;

- Case 5: The normal forces on planes P1 and P2 are compressive and the reaction of plane $\mathrm{P} 3$ is in tension. In other words, plane P3 is open and planes $\mathrm{P} 1$ and $\mathrm{P} 2$ are still in contact. To check the movement along the intersection line of planes $\mathrm{P} 1$ and $\mathrm{P} 2$, the force in this direction should be calculated. By solving the equilibrium equation and ignoring the plane $\mathrm{P} 3$, the values of normal forces on the planes $\mathrm{P} 1$ and $\mathrm{P} 2$ and the shear force are obtained. The corresponding sliding safety factor is calculated as follows:

$$
\begin{aligned}
& \mathrm{SF}= \\
& \frac{N_{1} \times \tan \left(\varphi_{1}\right)+c_{1} \times A_{1}+N_{2} \times \tan \left(\varphi_{2}\right)+c_{2} \times A_{2}}{\text { Shear force in direction of inter section } \mathrm{P} 1, \mathrm{P} 2} .
\end{aligned}
$$

- Case 6: The reactions of planes P1 and P3 are compressive and normal force of plane $\mathrm{P} 2$ is in tension. This case is similar to Case 5;

- Case 7: The reactions of planes P2 and P3 are compressive and normal force of plane $\mathrm{P} 1$ is in tension. This case is similar to Case 5;

- Case 8: All reactions are in tension and the wedge is detached from all its three supporting planes. The other sliding modes should be checked and if the assumption has been verified, it means that the wedge is completely unstable.

In Eqs. (6) and (7), $\varphi_{i}(i=1,2$, and 3$)$ is the friction angle of the $i$-th plane; $c_{i}(i=1,2$, and 3$)$ is the cohesion of the $i$-th plane; and $A_{i}(i=$ 1,2 , and 3 ) is the area of the $i$-th plane.

\subsection{Displacement of the wedge}

If the magnitude of the sliding safety factor is less than one, the wedge is unstable and will move. In order to calculate the displacement of the wedge, acceleration of the wedge should be calculated as:

$$
a(t)=\frac{\text { Driving force }(t)-\text { Stabilizing force }(t)}{\text { mass of the wedge }} .
$$

Then, the acceleration of wedge is decomposed to the $x, y$, and $z$ directions. Velocity and displacement 
of the wedge can be calculated by single and double integrations from computed acceleration time history of the wedge, respectively, based on the modified Newmark method. It should be mentioned that the displacement of the wedge will last until the velocity in the considered direction vanishes.

\section{Case study}

This study aims to investigate the abutment stability of an arch dam due to seismic loading. Luzzone dam is selected for this purpose. Luzzone dam is a double curved concrete dam completed in 1963. The dam elevation heightened $17 \mathrm{~m}$ between 1997 and 1998 and so the total height of the dam has reached $225 \mathrm{~m}$ [14]. Figure 2 shows a view of Luzzone dam.

The material properties of the concrete and rock foundation are presented in Table 2 [8]. The material damping ratio is considered to be five percent.

\subsection{Finite element model}

A 3-D finite element model including dam-foundation interaction has been developed to calculate the thrust forces applied by the dam to the wedge. For this purpose, 332 and 2984 8-node brick elements have been used to model dam body and foundation, respectively. Figure 3 shows the developed finite element model. This model includes 249 and 3797 nodes for the dam body and foundation, respectively. For modeling the reservoir, 1080 8-node fluid elements are used. The reservoir is truncated at a distance from the upstream face, which is about two times of the dam height.

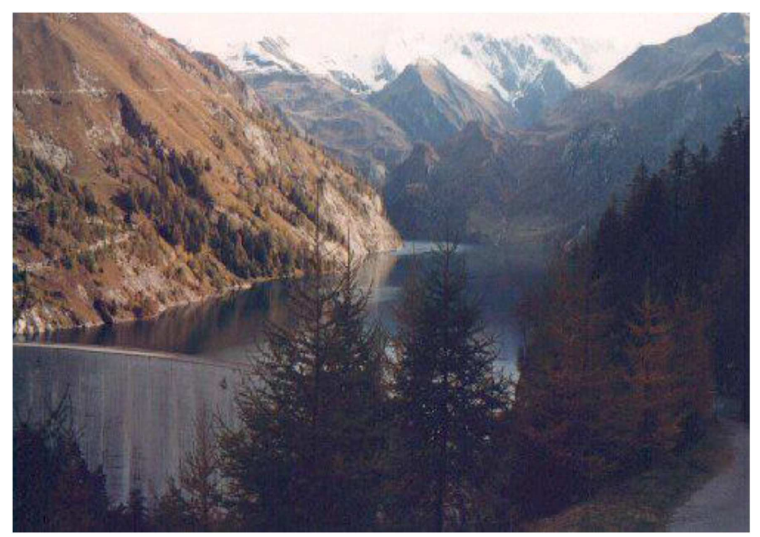

Figure 2. A view of Luzzone dam.

Table 2. Material properties of the dam concrete and the foundation rock [8].

\begin{tabular}{cccc}
\hline Materials & $\begin{array}{c}\text { Elastic } \\
\text { modulus } \\
(\mathbf{G P a})\end{array}$ & $\begin{array}{c}\text { Poisson's } \\
\text { ratio }\end{array}$ & $\begin{array}{c}\text { Density } \\
\left(\mathbf{k g} / \mathbf{m}^{\mathbf{3}}\right)\end{array}$ \\
\hline Concrete & 27 & 0.167 & 2400 \\
Foundation rock & 25 & 0.2 & 2600 \\
\hline
\end{tabular}

\subsection{Wedge definition}

As it is shown in Figure 4, three joint surfaces that intersect the abutment of the Luzzone dam create a contact wedge and its stability should be checked. The geometry and shear strength parameters of these discontinuity planes are presented in Table 3 . The volume and density of the wedge have been estimated $1.92 \times 10^{6} \mathrm{~m}^{3}$ and $2600 \mathrm{~kg} / \mathrm{m}^{3}$, respectively [8].

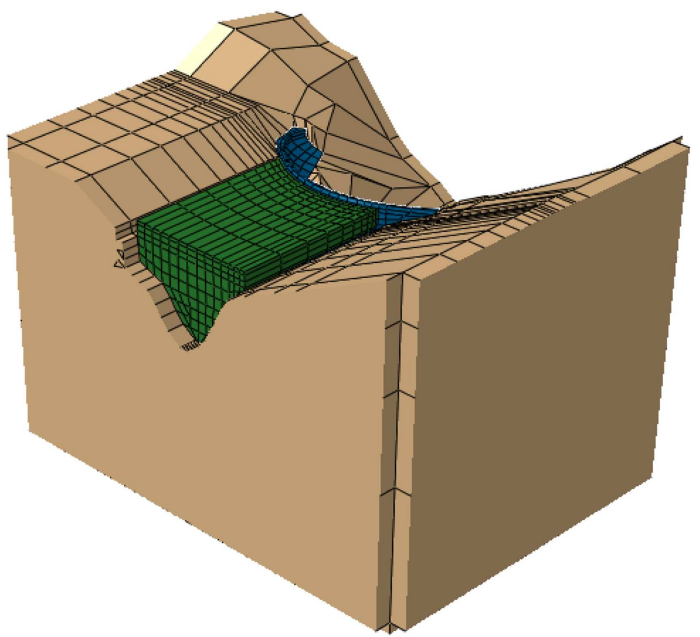

Figure 3. Dam-foundation-reservoir finite element model of Luzzone dam.

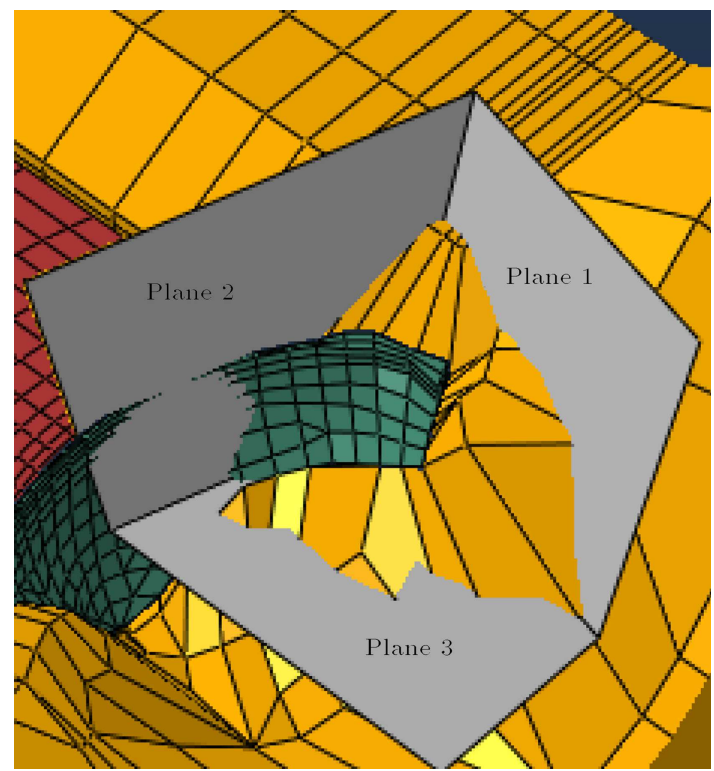

Figure 4. The rock wedge of the left abutment of Luzzone dam.

Table 3. Characteristics of the wedge.

\begin{tabular}{cccccc}
\hline Plane & $\begin{array}{c}\text { Friction } \\
\text { degree }\end{array}$ & Cohesion & $\begin{array}{c}\text { Area } \\
\left(\mathbf{m}^{\mathbf{2}}\right)\end{array}$ & $\begin{array}{c}\text { Dip } \\
\text { angle }\end{array}$ & $\begin{array}{c}\text { Dip } \\
\text { direction }\end{array}$ \\
\hline Plane 1 & 35 & - & 23300 & 65 & 5 \\
Plane 2 & 35 & - & 7200 & 76 & 280 \\
Plane 3 & 35 & - & 28650 & 0 & 0 \\
\hline
\end{tabular}




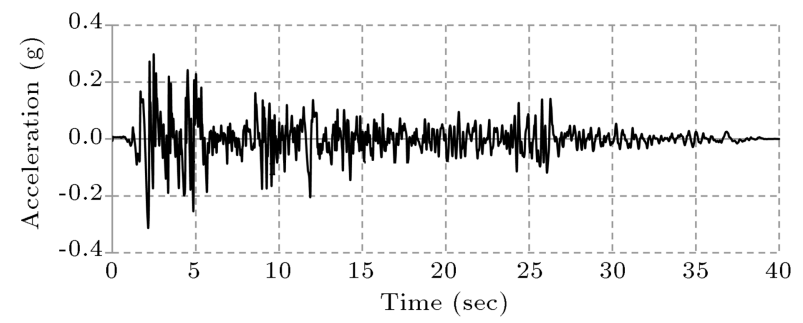

(a) Horizontal (cross-stream direction)

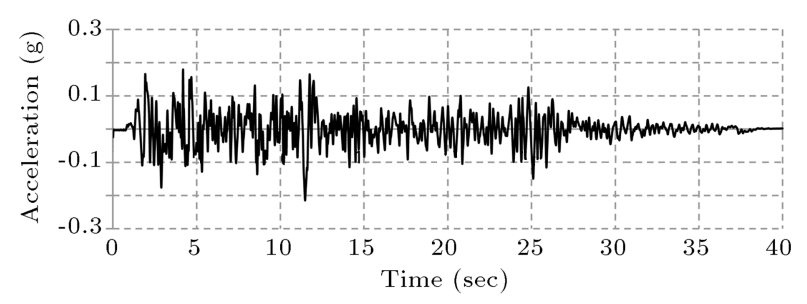

(b) Horizontal (stream direction)

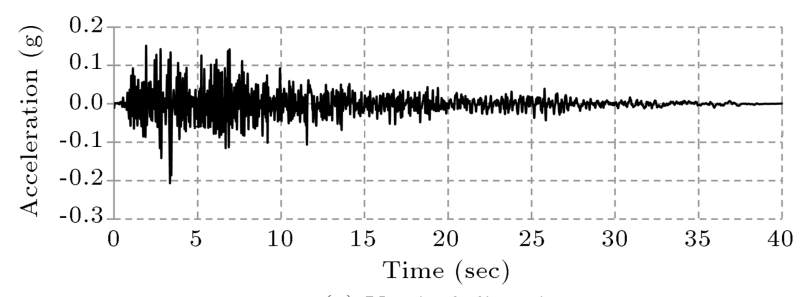

(c) Vertical direction

Figure 5. Ground acceleration in Imperial Valley earthquake (1941) [15].

\subsection{Applied forces}

The ground acceleration time histories of Kobe and Imperial Valley earthquakes are considered for the purpose of seismic analysis [15]. These records are normalized and the PGA of the records has changed from $0.1 \mathrm{~g}$ to $0.4 \mathrm{~g}$ in $0.05 \mathrm{~g}$ steps. The ground acceleration earthquakes are applied in cross-stream $(x-$ direction), stream ( $y$-direction), and vertically upward (z-direction) directions. The ground accelerations of Kobe and Imperial Valley are shown in Figures 5 and 6 , respectively. Thrust forces due to static and seismic loadings are obtained by using the finite element analysis of the developed finite element model.

\section{Results and discussion}

\subsection{Safety factors}

In order to compare the quasi-static and dynamic stability analyses, the corresponding sliding safety factors have been calculated. It should be emphasized that a reduction factor equal to $2 / 3$ was considered for horizontal and vertical PGAs in the quasi-static analysis. Moreover, the directions of applied horizontal acceleration $(\theta)$ change in 5-degree intervals to find the critical direction of seismic loads and the minimum safety factors.

For computing the thrust forces, four load cases

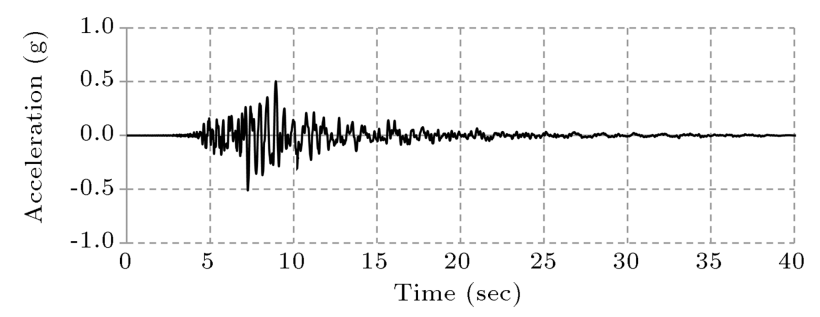

(a) Horizontal (cross-stream direction)

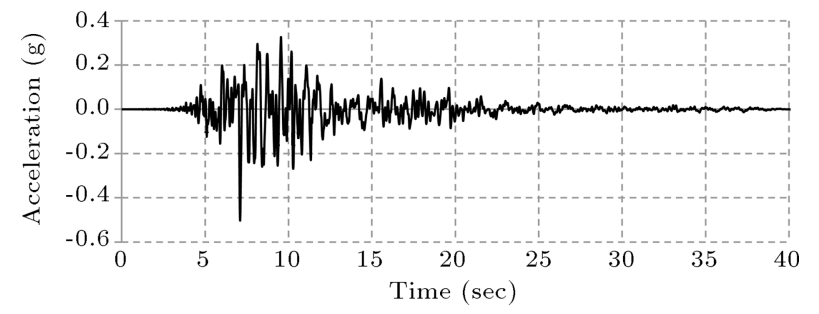

(b) Horizontal (stream direction)

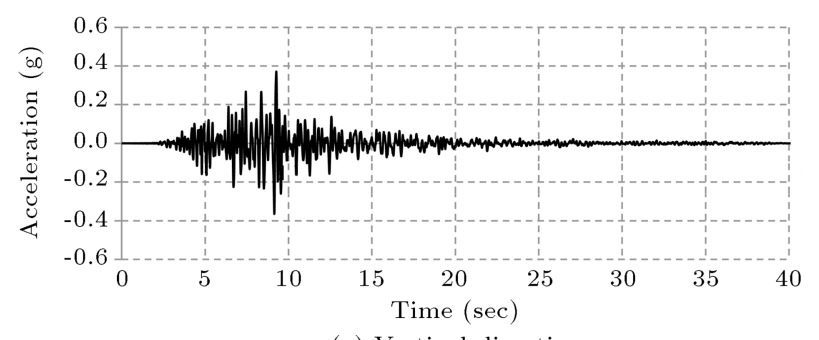

(c) Vertical direction

Figure 6. Ground acceleration in Kobe earthquake (1979) [15].

Table 4. Different load cases.

\begin{tabular}{cc}
\hline Analysis & Load cases \\
\hline Static & Static \\
& $\begin{array}{c}\text { Earthquake } x \text {-direction } \\
\text { Earthquake } y \text {-direction } \\
\text { Pseudo-static } \\
\end{array}$ \\
\hline
\end{tabular}

are defined, which are listed in Table 4. The first load condition is the static load case, which includes weight of the dam and hydrostatic pressure. Other conditions are pseudo-static cases in which a unit$\mathrm{g}$ acceleration is excited in each of the three global directions, respectively. Thrust forces due to quasistatic analysis are shown in Table 5 . The safety factors of wedge for quasi-static analysis for different values of Teta are shown in Table 6.

The time history of safety factors of stability analysis due to seismic loading is shown in Figure 7 for horizontal PGA of $0.4 \mathrm{~g}$.

\subsection{Comparison of dynamic and quasi-static analyses}

Figure 8 indicates the minimum of safety factors for dynamic and quasi-static analyses. The PGA of records has increased from $0.1 \mathrm{~g}$ to $0.4 \mathrm{~g}$ for this purpose. As it is shown in the figure, the quasi-static analysis is more conservative than dynamic analysis, 
Table 5. Thrust forces for quasi-static analysis.

\begin{tabular}{cccc}
\hline DAM-THRUST force vector & $\boldsymbol{T}_{\boldsymbol{x}}(\mathbf{M N})$ & $\boldsymbol{T}_{\boldsymbol{y}}(\mathbf{M N})$ & $\boldsymbol{T}_{\boldsymbol{z}}(\mathbf{M N})$ \\
\hline Static force vector & -2200.94 & -1189 & -2648.81 \\
Earthquake force vector $x$-direction & -31634.87 & -14005.4 & -8011.14 \\
Earthquake force vector $y$-direction & -21558.78 & -5513.24 & -6864.68 \\
Earthquake force vector $z$-direction & -63722.6 & -24107.31 & -20879.45 \\
\hline
\end{tabular}

Table 6. Safety factor of the wedge for quasi-static analysis ( $\mathrm{PGA}=0.4 \mathrm{~g})$.

\begin{tabular}{cccccccc}
\hline Teta & SF & Teta & SF & Teta & SF & Teta & SF \\
\hline 0 & 1.032 & 90 & 1.2476 & 180 & 1.1385 & 270 & 0.8288 \\
5 & 1.0705 & 95 & 1.2166 & 185 & 1.1758 & 275 & 0.812 \\
10 & 1.1279 & 100 & 0.98 & 190 & 1.2136 & 280 & 0.7973 \\
15 & 1.1898 & 105 & 0.9655 & 195 & 1.2498 & 285 & 0.7846 \\
20 & 1.2542 & 110 & 0.954 & 200 & 1.2814 & 290 & 0.7736 \\
25 & 1.3186 & 115 & 0.9455 & 205 & 1.3049 & 295 & 0.7642 \\
30 & 1.3791 & 120 & 0.9402 & 210 & 1.3167 & 300 & 0.7563 \\
35 & 1.4315 & 125 & 0.938 & 215 & 1.3139 & 305 & 0.7499 \\
40 & 1.4716 & 130 & 0.939 & 220 & 1.295 & 310 & 0.7448 \\
45 & 1.4959 & 135 & 0.9432 & 225 & 1.2609 & 315 & 0.7411 \\
50 & 1.5032 & 140 & 0.9508 & 230 & 1.214 & 320 & 0.7387 \\
55 & 1.4942 & 145 & 0.9618 & 235 & 1.1582 & 325 & 0.7376 \\
60 & 1.4718 & 150 & 0.9763 & 240 & 1.0978 & 330 & 0.7379 \\
65 & 1.4396 & 155 & 0.9944 & 245 & 1.0363 & 335 & 0.7395 \\
70 & 1.4016 & 160 & 1.0161 & 250 & 0.9766 & 340 & 0.7426 \\
75 & 1.3611 & 165 & 1.0416 & 255 & 0.9205 & 345 & 0.7473 \\
80 & 1.3209 & 170 & 1.0707 & 260 & 0.8698 & 350 & 0.7536 \\
85 & 1.2826 & 175 & 1.1031 & 265 & 0.8479 & 355 & 0.7617 \\
Minimum & 325 & 0.7376 & & & & & \\
safety factor & & & & & & & \\
\hline & & & & & & &
\end{tabular}

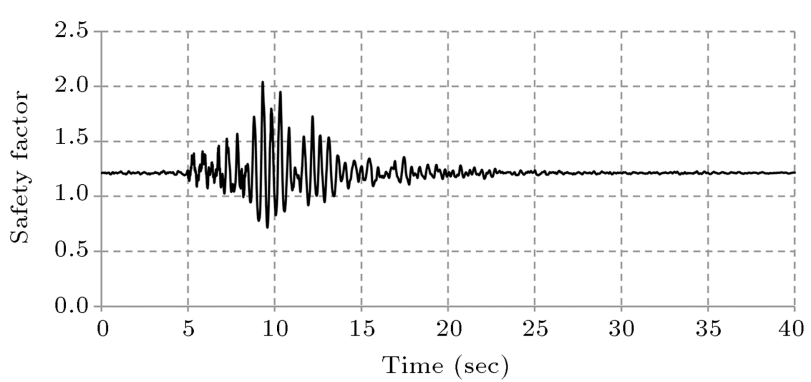

Figure 7. The safety factor of wedge due to seismic loading $(\mathrm{PGA}=0.40 \mathrm{~g})$.

which is expected based on the reduction factor of $2 / 3$ in the quasi-static analysis. The obtained results reveal that the safety factor of 1.14 can be considered as a limit value, which corresponds to wedge movement in dynamic analysis.

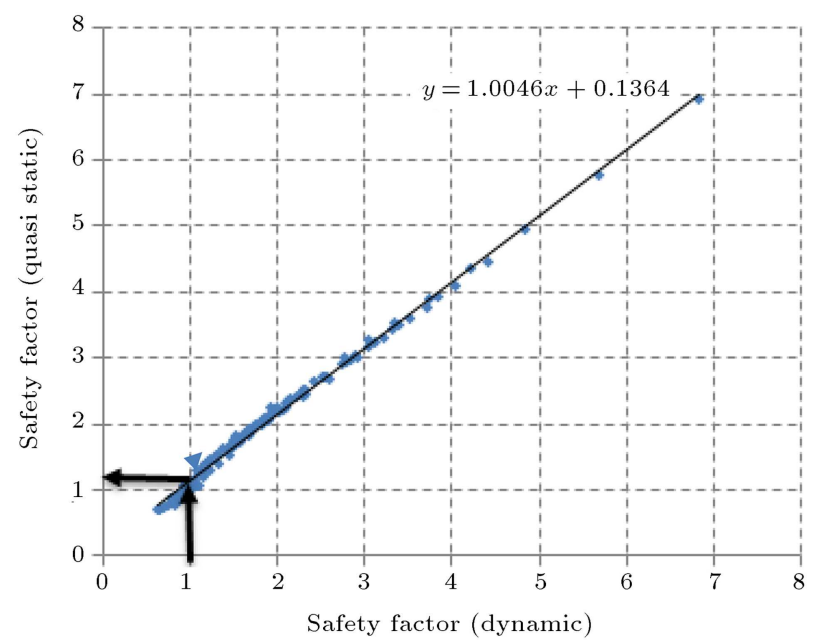

Figure 8. The minimum safety factor for quasi-static and dynamic analyses. 


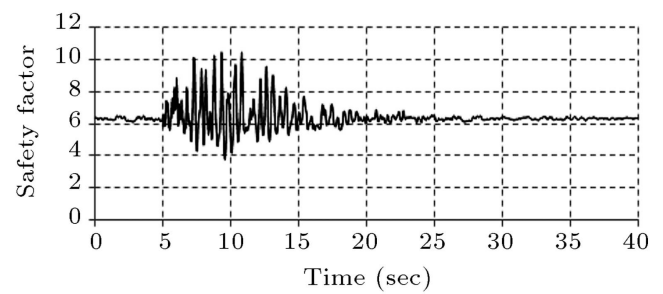

(a) Combo 1

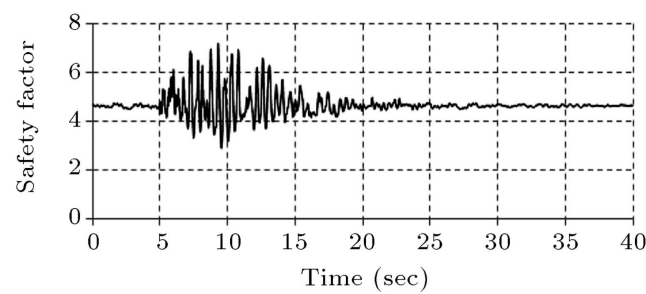

(c) Combo 3

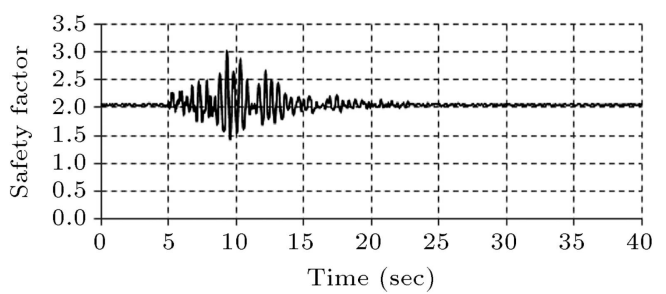

(e) Combo 5

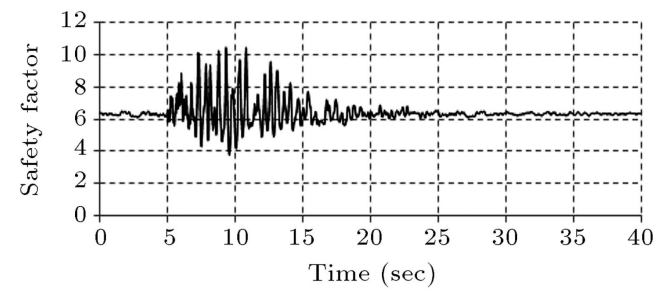

(b) Combo 2

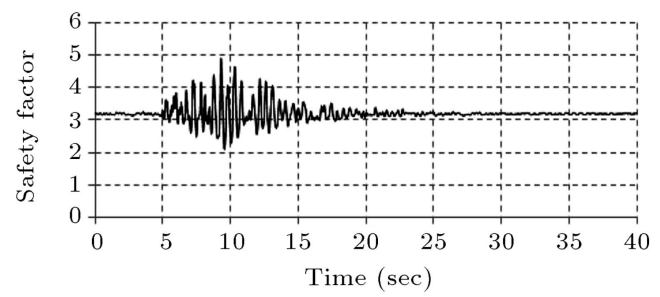

(d) Combo 4

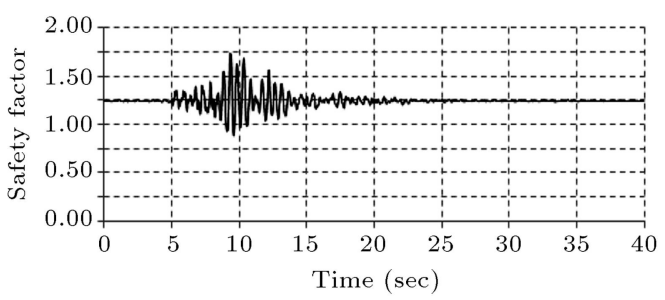

(f) Combo 6

Figure 9. Safety factor of the wedge for different load combinations (PGA $=0.40 \mathrm{~g}$ ).

Table 7. Load combination.

\begin{tabular}{ccccc}
\hline & \multicolumn{4}{c}{ Load } \\
\cline { 2 - 5 } Combination & Weight & Uplift & EQ & $\begin{array}{c}\text { Thrust } \\
\text { force }\end{array}$ \\
\hline Combo 1 & 1.0 & 0.0 & 1.0 & 1.0 \\
Combo 2 & 1.0 & 0.2 & 1.0 & 1.0 \\
Combo 3 & 1.0 & 0.4 & 1.0 & 1.0 \\
Combo 4 & 1.0 & 0.6 & 1.0 & 1.0 \\
Combo 5 & 1.0 & 0.8 & 1.0 & 1.0 \\
Combo 6 & 1.0 & 1.0 & 1.0 & 1.0 \\
\hline
\end{tabular}

\subsection{Uplift pressure effects}

In order to investigate the uplift pressure effects on the safety factor of the wedge, 6 load combinations are considered, which are listed in Table 7. The time histories of safety factors due to seismic loading for horizontal PGA of $0.4 \mathrm{~g}$ for different load combinations are shown in Figure 9. The obtained results show that the uplift pressure can have profound effects on the abutment stability of arch dams (Figure 10).

\subsection{Displacement of wedge}

The obtained safety factor for the load combination 6 indicates that the wedge is unstable. The calculated displacement of the wedge is shown in Figure 11.

Figure 12 shows the time history of safety factor for the Kobe earthquake. The PGA of applied acceleration time histories is considered to be $0.40 \mathrm{~g}$ and the

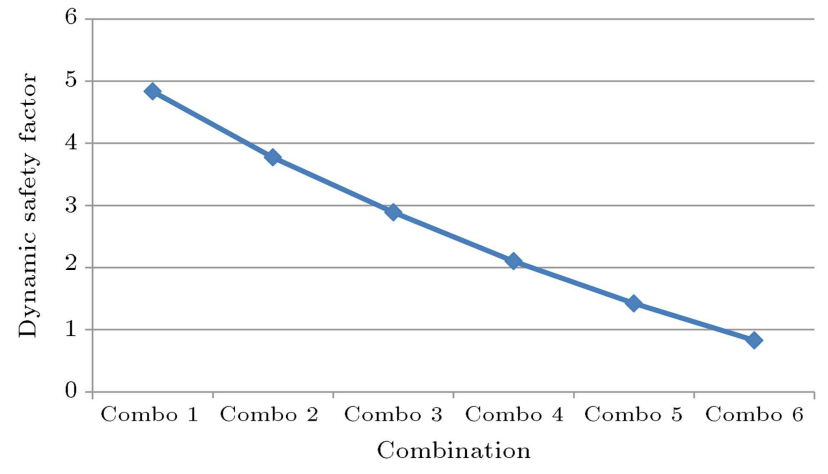

Figure 10. The effect of uplift pressure on the minimum sliding safety factor.

uplift pressure is fully applied to the supporting planes. As it is shown, the safety factor is less than 1 for some periods of time.

\section{Conclusion}

In this study, the abutment stability analysis of an arch dam is carried out to investigate the wedge instability and its probable movement. For decades, the quasistatic method due to its simple approach has been used by most the of dam designers. In this study, the dynamic method is used and the obtained time history of safety factors is compared to the quasistatic results. In this approach, all three components of earthquake ground motions can be applied to the 

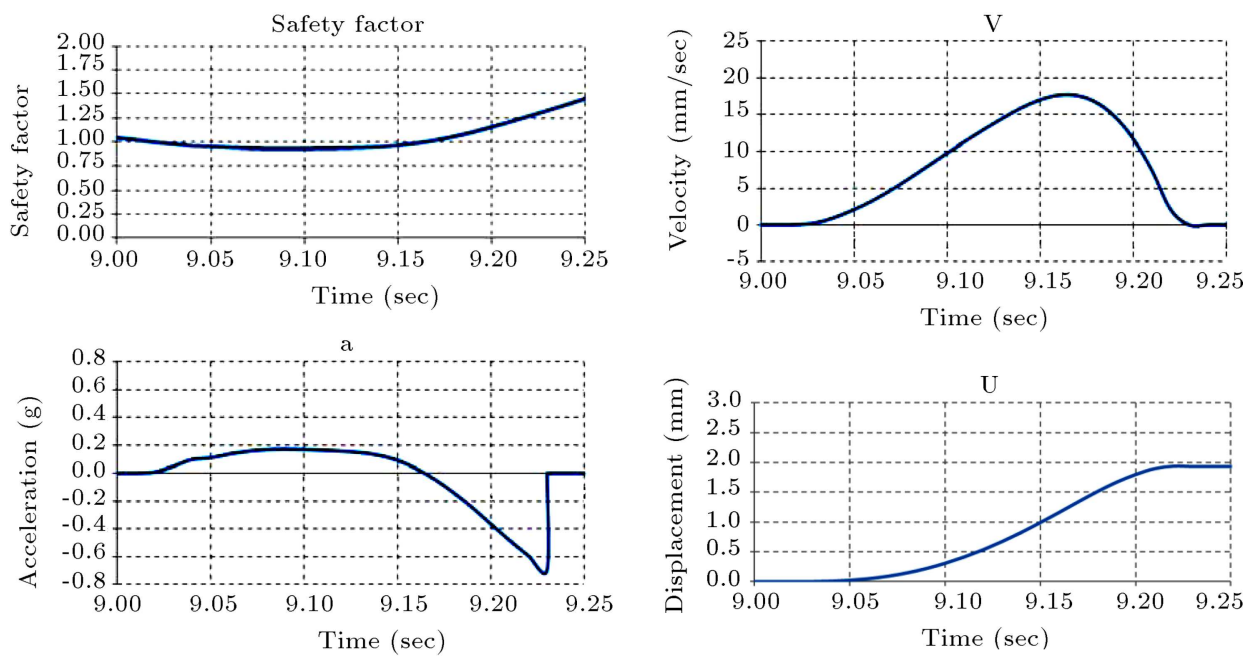

Figure 11. Safety factor, acceleration, velocity, and displacement of the wedge for load combination 6 .
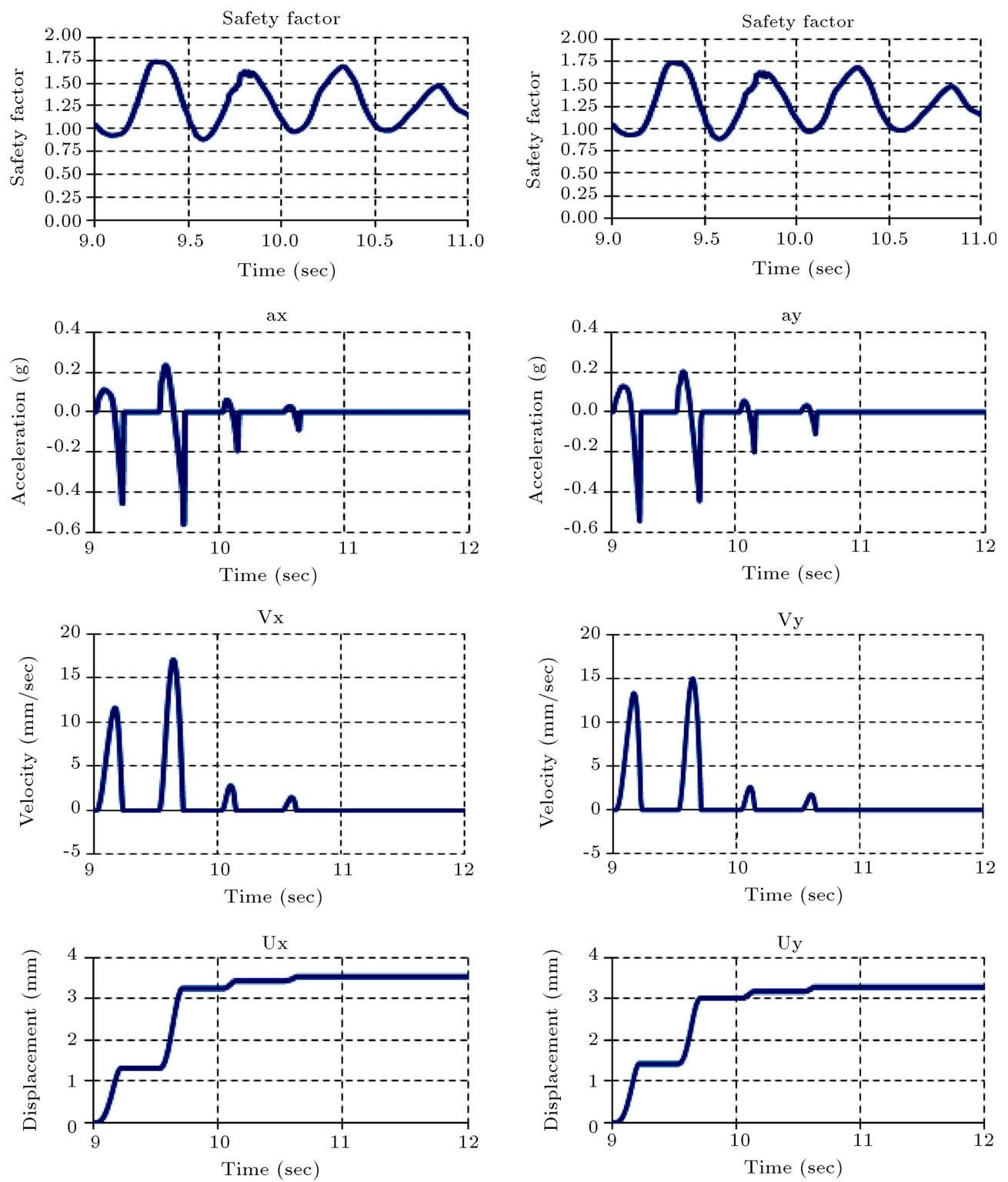

Figure 12. Safety factor, acceleration, velocity, and displacement of the wedge for load combination 6 . 
model simultaneously, the time history of thrust forces can be considered, and the magnitude and direction of probable wedge movements in seismic loadings can be calculated based on the safety factor time history. It should be mentioned that in the dynamic method, the time history of safety factor, the number of times that safety factor goes less than one, and the cumulative time that safety factor is less than one as well as the magnitude and direction of probable wedge movement can be calculated and shed more lights on the stability analysis, which is not possible in the quasi-static method.

Finding a correlation between the dynamic and quasi-static methods is one the most important issues, which is investigated it this study. The obtained results show that quasi-static method is more conservative and the safety factor of about 1.1 can be considered as a limit value, which corresponds to wedge movement in dynamic analysis. The importance of uplift pressure effects on the abutment stability is investigated as well. It is shown that the uplift pressure can play a key role in the abutment stability analysis and it is necessary to control the uplift pressure and seepage in arch dam foundations.

\section{References}

1. Goodman, R.E. and Powel, C. "Investigations of blocks in foundations and abutments of concrete dams", $J$. of Geotech Geoenviron., 129(2), pp. 105-121 (2003).

2. Duncan, J. "State of the art: limit equilibrium and finite-element analysis of slopes", J. of Geotechnical Eng., 122(7), pp. 577-596 (1996).

3. Griffiths, D. and Lane, P. "Slope stabilityanaly sis by finite elements", J. of Geotechnique, 49(3), pp. 387-403 (1999).

4. Yu, X., Zhou, Y.F. and Peng, S.Z. "Stability analyses of dam abutments by 3D elasto-plastic finite-element method: a case study of Houhe gravity-arch dam in China", Int. J. of Rock Mechanics \& Mining Sciences., 42, pp. 415-430 (2005).

5. Londe, P. "The Malpasset dam failure", The International Workshop on dam Failure, Indiana (1987).

6. US. Army Corps of Engineers (USACE). "Timehistory dynamic analysis of concrete hydraulic structures", Chapter 2: Analytical Modeling of Concrete Hydraulic Structures, 3: Time-History Numerical Solution Techniques, EM 1110-2-6051 (2003).

7. US. Army Corps of Engineers (USACE). "Earthquake design and evaluation of concrete hydraulic struc- tures", Chapter 4: Methods of Seismic Analysis and Structural Modeling, EM-1110-2-6053 (2007).

8. Sohrabi Gilani, M., Feldbacher, R. and Zenz, G. "Stability of dam abutment including siesmic loading", 10th ICOLD Benchmark Workshop, Paris (2009).

9. Zenz, G., Goldgruber, M. and Feldbacher, R., Seismic Stability of a Rock Wedge in the Abutment of an Arch Dam (2012).

10. Lin, P., Huan, B., Li, Q. and Wang, R.K. "Hazards and seismic reinforcement analysis for typical large dams following the Wenchuan earthquake", J. of Engineering Geology, 194 (2014).

11. Lin, P., Zhou, W. and Liu, H. "Experimental study on cracking, reinforcement, and overall stability of the Xiaowan super-high arch dam", J. of Rock Mechanics and Rock Engineering, 48, pp. 819-841 (2014).

12. Newmark, N. "Effect of earthquakes on dams and embankments", J. of Geotechnique Mileston in Engineering, 1(2), pp. 109-129 (1965).

13. Londe, P. "Analysis of the stability of rock slopes", $J$. of Quartery Jornal of Engineering Geology and Hydrogeology., 1, pp. 93-124 (1973).

14. Stuchy, Ltd. "Stability of a dam abutment including siesmic loading", 10th Benchmark Workshop on $\mathrm{Nu}$ merical Analysis of Dams (2009).

15. PEER Strong Motion Database, http://www.peer. berkeley.edu.

\section{Biographies}

Hasan Mostafaei is a PhD Candidate in Civil Engineering Department of Isfahan university of Technology. He has worked on the abutment stability analysis of arch dams, including seismic loadings, in these recent years.

Morteza Sohrabi Gilani is an Assistant Professor in Civil Engineering Department of Guilan University. Seismic responses of gravity and arch dams and stability of dam abutments, including seismic loading, have been in his research interests in these recent years.

Mohsen Ghaemian is Professor in Civil Engineering Department of Sharif University of Technology. His current activity is on dynamic responses of gravity and arch dams. Dam reservoir interaction effects, seismic response of dams due to non-uniform excitations, and nonlinear behavior of concrete dams have been in his research interest in these recent years. 